\title{
Weed Population Assessment in Wheat at Central Highlands of Ethiopia
}

\author{
Shugute Addisu, Zahara Mohammed, Gebre Kidan Feleke \\ Department of Crop Protection, Ethiopia Institute of Agricultural Research, Debre Zeit Agricultural Research Center, Debre Zeit, Ethiopia \\ Email address: \\ ashugute@yahoo.com (S. Addisu), zehara2008@yahoo.com (Z. Mohammed), gebrekidan336@gmail.com (G. K. Feleke)

\section{To cite this article:} \\ Shugute Addisu, Zahara Mohammed, Gebre Kidan Feleke. Weed Population Assessment in Wheat at Central Highlands of Ethiopia. \\ American Journal of Agriculture and Forestry. Vol. 7, No. 1, 2019, pp. 17-22. doi: 10.11648/j.ajaf.20190701.13
}

Received: December 1, 2018; Accepted: January 10, 2019; Published: February 13, 2019

\begin{abstract}
Study was conducted on Weed Population Assessment in Wheat at Adea, Gimbichu, Minjar shenkora, Akaki, Boro and Lume Districts in Central Highlands of Ethiopia during, 2014/15 main cropping season to determine the distribution of weed species in wheat growing areas of central highlands of Ethiopia and to record the weed infestation level on wheat crop production. Depending on the area coverage of Wheat in each Districts seven to three kebeles, again in each kebele six to four from Wheat fields samples were taken using $0.5 \times 0.5 \mathrm{~m}$ quderate and GPS instrument. The frequency, abundance and dominance regarding different aspects of weeds were calculated. The result revealed that 45 weed species belonging to 33 families as weeds of wheat for each species was calculated. The 5 major families based on number of taxa were: Poaceae (14), Asteraceae (7), three species each under Polygonaceae and Solanaceae, and Papilionaceae (2), totally they contain 66\% of the total weed flora. The most frequent, abundant and dominant weed species were found to be setaria pumila, Plantago lanceolata, Bromus pecpectinatus, Cyperus rotudus, Xanthium strumarium L. and Snowdenia polystachya. Greater than $60 \%$ similarity index of weed communities was registered across all locations sampled.
\end{abstract}

Keywords: Distribution, Districts, Importance, Weeds, Wheat Field

\section{Introduction}

Wheat is an important cereal crop and is gaining popularity all over the world and especially in Ethiopia. Due to increase in population and food prices, higher yield of the wheat can play a vital role in stabilizing the food prices directly or indirectly. Management of many factors can significantly contribute in increasing the grain yield of wheat in Ethiopia. Among these factors, weed management is an important factor and can increase the wheat yield by million ton in Ethiopia. Weeds are an important obstacle to crop production, particularly in low-input and/or organic systems $[2,6]$. Weeds are prominent yield reducers that are, in many situations, economically more important than insects, fungi or other pest organisms [9]. Weed management approaches used in Ethiopia are mostly dependent largely on herbicide application or manual weeding after critical period of weed competition and thus resources are wasted without any significant yield advantage. Reference [3] reported that the aim of weed management is to keep the weed community at an acceptable level rather than to keep the crop totally free of weeds. Weeds can be suppressed in wheat through variety of techniques as single method of weed control is not sustainable in our country. As crop-weed interference is inevitable therefore a judicious use of herbicides and integration of cultural methods may prove more effective. However due to ignorance and lack of knowledge the farmers blindly apply herbicides without considering its economics, resistance, health and environment. Chemical weed management should not be relied upon as the sole method of protecting crops from weeds in Ethiopian conditions. Herbicides should be used in combination with good preventative, physical and cultural practices.

However, a long-term effective weed management strategy is based on the practical application of the ecological concept of maximum diversification of disturbance, which means diversifying crops and cultural practices in a given agroecosystem as much as possible [7]. These results in a continuous disruption of weed ecological niches and hence effects in a minimized risk of weed flora evolution towards the presence of a limited number of highly competitive species. Besides this, a highly diversified cropping system 
also reduces risk of the development of herbicide-resistant weed populations.

Although crop yield losses from weeds vary from crop to crop and from region to region, because of biotic and abiotic factors, it has been estimated that weeds cause a yield loss of about $10 \%$ in developed countries and $25 \%$ in the least developed countries $[1,10]$

Before making a decision about a solution to a weed problem it is needed to survey the area to document the indigenous knowledge of the community and also to visually confirm the existing situation. Weed surveys made in the past in Ethiopia were general weed population surveys and collections. The most widespread and problematic weed species were determined based on observation and information gathered from farmers $[4,5]$. Surveys were made by visual observation of weeds, noting an increase or decrease over time in specific crops, and taking a quadrat of a certain size in several places at random at any one time and counting the particular weed species [5]. According to [8, 12], there are two kinds of surveys. One is a qualitative determination of weeds which involves simply determining the weed species, and identifying farmers' problems and control practices in an area. It does not indicate the infestation level or the degree of economic importance of the weeds. The other kind, a quantitative determination of weed species, is more informative and better recognized than the qualitative determination, as it reports characteristics or parameters which can be used to describe a weed community quantitatively. These parameters comprise frequency of species, abundance, dominance of the species, and a similarity of species in different crops and/or agro-climatic conditions $[8,12]$. Therefore, weed surveys in wheat field is needed determine the frequency, abundance, dominance and establish an efficient weed management system.

Hand weeding of grass weeds is difficult during early growth stages of the broadcast crop due to similar morphology with wheat. Ethiopian farmers tend to delay hand weeding until the weeds are distinguished from crop plants, thus exposing the crop to weed competition for an extended period [11].

This survey information initiate short and long term research on control measures based on the weed population diversity obtained from survey, to determine the distribution of weed species in wheat growing areas of central highlands of Ethiopia and to record the weed infestation level and severity on wheat crop production in the respective administrative districts of the study areas.

\section{Material and Methods}

A survey of the weed flora in major wheat growing area of central high lands of Ethiopia was carried out during 2014/2015 cropping season starting from mid of August to early September. Based on climatic and topographic conditions, the area has been locally classified into highland (21\%), mid highland (65\%) and lowland (14\%). Soils of the study area are black, red and intermediate types. In the area, mixed farming system is mainly practiced with large dependence on cereal crops (tef, wheat, Chickpea, Lentil and barley) farming. But in terms of crop production tef stands first followed by Wheat and Chickpea in the six districts, accounting for the $54 \%$ of the cultivable land.

The field assessment was covered the major agroecological zones and selected as follows: first a stratified sampling method based on altitude was chosen, a classification commonly carried out in relation to wheat research in Ethiopia. Second representative districts within each altitude zone were selected, then representative peasant associations within each district, and villages within association. Third fields were selected regardless of size, on the grounds of accessibility to road and whether it carried the required crop or crop combination.

The field assessment data was collected using GPS 60 GARMIN. Using this instrument, the latitude and longitude (x, y) co-ordinates of the waypoints at every $5-10 \mathrm{kms}$ interval and at each sampling points, the occurrence, spread, distribution, and abundance of the major agricultural weeds in different habitats of each area was properly recorded. Scale of infestation was visually observed and measured as abundant, frequent, and dominance depending on their level of infestation. Weed survey information is collected and compiled in to maps showing the distribution and severity of infestation.

Weed specimen collection and identification manuals, and plant press were used to collect the samples. Data was recorded including specimen information such as botanical name, local name, habitat, soil type, date of collection and collector name etc. Weed specimen was supplemented with digital camera photos showing different growth stages of the plant that can be easily reprinted and used in field book development, demonstration and training programs. The information gathered was used to develop management options.

\section{Data Collection and Analysis}

To determine the weed nature of the problem in wheat communities, quantitative measures were calculated for each weed species in wheat based on the procedures followed by Thomas (1985) and Taye and Yohannes (1998).

A. Frequency: is the percentage of sampling spots in which a particular weed species is found.

$$
\mathrm{F}=100 * \mathrm{X} / \mathrm{N}
$$

Where, $\mathrm{F}=$ frequency of particular weed species, $\mathrm{X}=$ number of samples in which a particular weed species occurs, $\mathrm{N}=$ total number of samples.

B. Abundance: is the population density of a weed species expressed as the number of individuals of that species per unit area.

$$
(\mathrm{A})=\left(\sum \mathrm{w}\right) / \mathrm{N}
$$

Where, $\mathrm{A}=$ abundance, $\sum \mathrm{w}=$ sum of individuals of a particular weed species across all samples, $\mathrm{N}=$ total number of samples. 
C. Dominance: Abundance of an individual weed species in relation to total weed abundance.

$$
\mathrm{D}=\mathrm{A} * 100 /\left(\sum \mathrm{W}\right)
$$

Where, $\mathrm{D}=$ dominance of a particular species, $\mathrm{A}=$ Abundance of the same species, $\sum \mathrm{w}=$ total abundance of all weed species

D. Similarity index (community index): is the similarity of weed communities between different locations, crops, soil types or seasons. As described by Taye and yohannes (1998).

$$
\mathrm{SI}=100 * \mathrm{Epg} /(\mathrm{Epg}+\mathrm{Epa}+\mathrm{Epb})
$$

Where; SI = Similarity index, Epg = number of species found in both locations, Epa = number of species found only in location.

$\mathrm{Epb}=$ number of species found only in locations II

\section{Results and Discussion}

\subsection{Weed Flora of Wheat Fields}

A total of 44 different weed taxa were recorded from Wheat fields of Gimbichu, Akaki, Ada, Lume, Bora and Minjar districts of which 44 were identified to the species level. Among those 38 species were annuals, and 6 annuals/perennials. The survey results also showed that, grassy weeds appeared to dominate over broadleaved weed species. The 11 major families based on number of taxa were: Poaceae (14), Asteraceae (7), three species each from Polygonaceae and Solanaceae, two species from Papilionaceae. The above contain $66 \%$ of the total weed flora (Table 1). Therefore, the most dominant families' interms of number of taxa reperesented were Poaceae and Asteraceae.

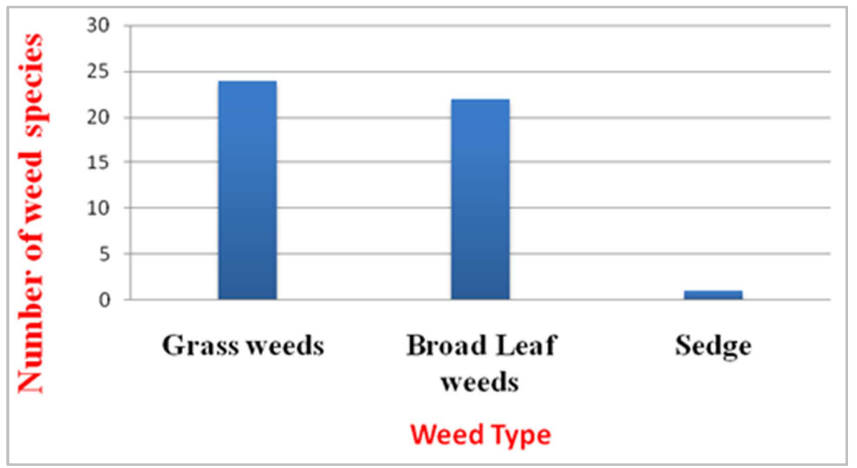

Figure 1. Number of weed species from wheat fields of Gimbichu, Akaki, Ada, Lume, Bora and Minjar districts, 2014/15.

The result also showed that in all districts, grasses weed species appeared to dominate over broadleaved and sedges. The greater number of species in Poaceae, Asteraceae, Polygonaceae, Solanaceae and Papilionaceae might be due to their adaptability under a wider range of environmental conditions and soil types, growth behaviour, prolific seed production, long lasting dormancy and highly competitive ability of weed species present in these families. However, the number and the identity of the weeds varied in different wheat fields.

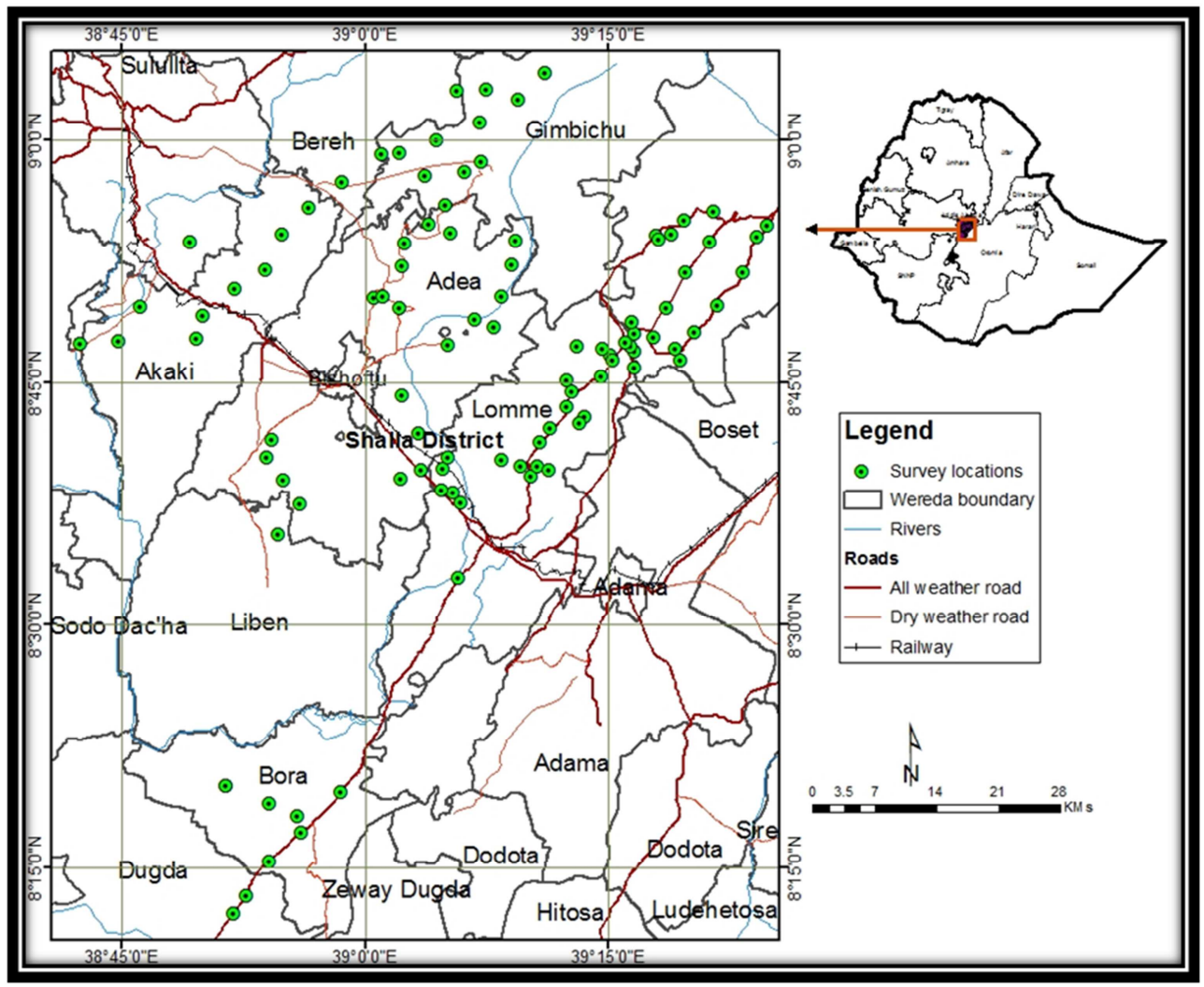

Figure 2. Weed survey information collected were compiled in to maps showing the distribution of weed species. 
Table 1. Number of major weed species by families.

\begin{tabular}{llll}
\hline No & Family & Number of weed species & \% of weed flora \\
\hline 1 & Poaceae & 14 & 32 \\
2 & Asteraceae & 7 & 16 \\
3 & Papilionaceae & 2 & 4.5 \\
4 & Polygonaceae & 3 & 6.8 \\
5 & Solanaceae & 3 & 6.8 \\
Total & & 29 & 66 \\
\hline
\end{tabular}

\subsection{Frequency, Abundance and Dominance of Weeds in Wheat Fields}

The importance of weed species was determined by calculating the abundance and dominance value. In the Ada, Minjar, Lume, Akaki, Gimbichu and Bora, districts frequency of Setaria Pumila was extremely high, i.e., $81.8 \%, 70 \%, 63 \%, 61.8 \%, 61 \%$ and $46.7 \%$ compared to other major weed species, respectively. Frequency and dominance of individual weed species were calculated and ranged from 0.056 to $64 \%$, and 0.03 to $21.6 \%$, respectively (Table 2).
The most frequently distributed species was Setaria pumila 64 percent of the samples followed by Plantago lanceolata, Bromus pecpectinatus, Cyperus rotudus, Xanthium strumarium, Snowdenia polystachya, Convolvulus arvensis, Scorpiru muricatus, Oxygonum sinuatum which scored frequencies ranging from 12.4 to $45.7 \%$. Setaria pumila was also found to be the most abundant $\left(31 \mathrm{p} / \mathrm{m}^{2}\right)$ in wheat fields of the area.

In general, there were positive and significant correlations between frequency, abundance and dominance. Frequency of individual weed species ranged from 0.56 to $64 \%$, while the dominance level ranged from 0.03 to $21.6 \%$ (table 2 ).

Table 2. Weed species and their, Frequency (F) Abundance (A) and Dominance (D).

\begin{tabular}{|c|c|c|c|c|}
\hline No & Name of Species & Frequency & Abundance & Dominance \\
\hline 1 & Setaria pumila (Poir. Roem. \& Schult.) & 64 & 43.2 & 21.6 \\
\hline 2 & Plantago lanceolata & 45.7 & 33.8 & 14.5 \\
\hline 3 & Bromus pecpectinatus & 33.6 & 31 & 14.8 \\
\hline 4 & Cyperus rotudus $l$ & 26.1 & 20.6 & 11.1 \\
\hline 5 & Xanthium strumarium $L$. & 19.2 & 3.08 & 1.55 \\
\hline 6 & Snowdenia polystachya & 17 & 2.65 & 1.39 \\
\hline 8 & Scorpiru muricatus & 13 & 4.11 & 1.84 \\
\hline 9 & Oxygonum sinuatum & 12.4 & 3.4 & 1.75 \\
\hline 10 & Galium spurium L.Var & 11.1 & 3.31 & 1.75 \\
\hline 11 & Digitaria abyssinica & 10.9 & 2.76 & 1.51 \\
\hline 12 & Argemon mexicana & 10.7 & 1.74 & 0.93 \\
\hline 13 & Amaranthus hybridus & 9.86 & 1.07 & 0.54 \\
\hline 14 & Heliotropium zeylanicum & 9.43 & 1.82 & 0.85 \\
\hline 16 & Lolium temulentus & 8.8 & 1.5 & 0.84 \\
\hline 17 & commelina benghalensis & 8.49 & 0.9 & 0.51 \\
\hline 18 & Rumex abyssinicus & 7.81 & 1.24 & 0.51 \\
\hline 19 & Galinsoga parviflora & 7.89 & 0.96 & 0.44 \\
\hline 20 & Phalaris paradoxa & 7.53 & 0.79 & 0.35 \\
\hline 21 & Guizotia scabra & 6.13 & 1.96 & 1.01 \\
\hline 22 & Sonchus asperl L. & 5.07 & 0.91 & 0.55 \\
\hline 23 & Anagalis & 4.31 & 0.57 & 0.28 \\
\hline 24 & Leucas martinicensis Jacq. S. Moore & 4.31 & 0.56 & 0.28 \\
\hline 25 & Solanium nigrum & 4.11 & 0.62 & 0.32 \\
\hline 26 & Raphanus raphanistrun & 4.09 & 2.95 & 1.48 \\
\hline 27 & chenopodium procerum & 3.48 & 1.06 & 0.45 \\
\hline 28 & Avena fatua & 3.44 & 1.65 & 0.93 \\
\hline 31 & Dinebra retroflexa & 2.73 & 2.08 & 0.85 \\
\hline 32 & Polygonum nepalense & 2.6 & 0.52 & 0.24 \\
\hline 33 & Nicandra physaloides & 2.51 & 0.73 & 0.39 \\
\hline 34 & Cynodon dactylon & 2.28 & 0.24 & 0.1 \\
\hline 35 & Sorghum arundinacensis & 1.29 & 0.18 & 0.1 \\
\hline
\end{tabular}




\begin{tabular}{lllll}
\hline No & Name of Species & Frequency & Abundance & Dominance \\
\hline 36 & Tagetes minuta L. & 1.29 & 0.18 & 0.1 \\
37 & Parthnium hysterophus & 1.25 & 0.1 & 0.07 \\
38 & Raninculus arvense & 1.17 & 0.37 & 0.22 \\
39 & Launaea cornuta & 0.91 & 0.11 & 0.05 \\
40 & Ganaphalium & 0.91 & 0.11 & 0.05 \\
41 & Datura stramonium L. & 0.88 & 0.13 & 0.07 \\
42 & Elusinia indica & 0.86 & 0.35 & 0.18 \\
43 & Anthemes & 0.56 & 0.09 & 0.03 \\
44 & Andropogon & 0.56 & 0.09 & 0.03 \\
\hline
\end{tabular}

Table 3. Similarity Index.

\begin{tabular}{llllll}
\hline Locations (Districts) & Akaki & Ada & Bora & Gimbichu & Lume \\
\hline Akaki & 100 & 74.07 & 63.3 & 70.6 & 82.7 \\
Ada & & 100 & 70.1 & 67.2 & 82.9 \\
Bora & & 100 & 64.7 & 68.5 \\
Gimbichu & & & 100 & 69.1 \\
Lume & & & & 79.6 \\
Minjar & & & & & \\
\hline
\end{tabular}

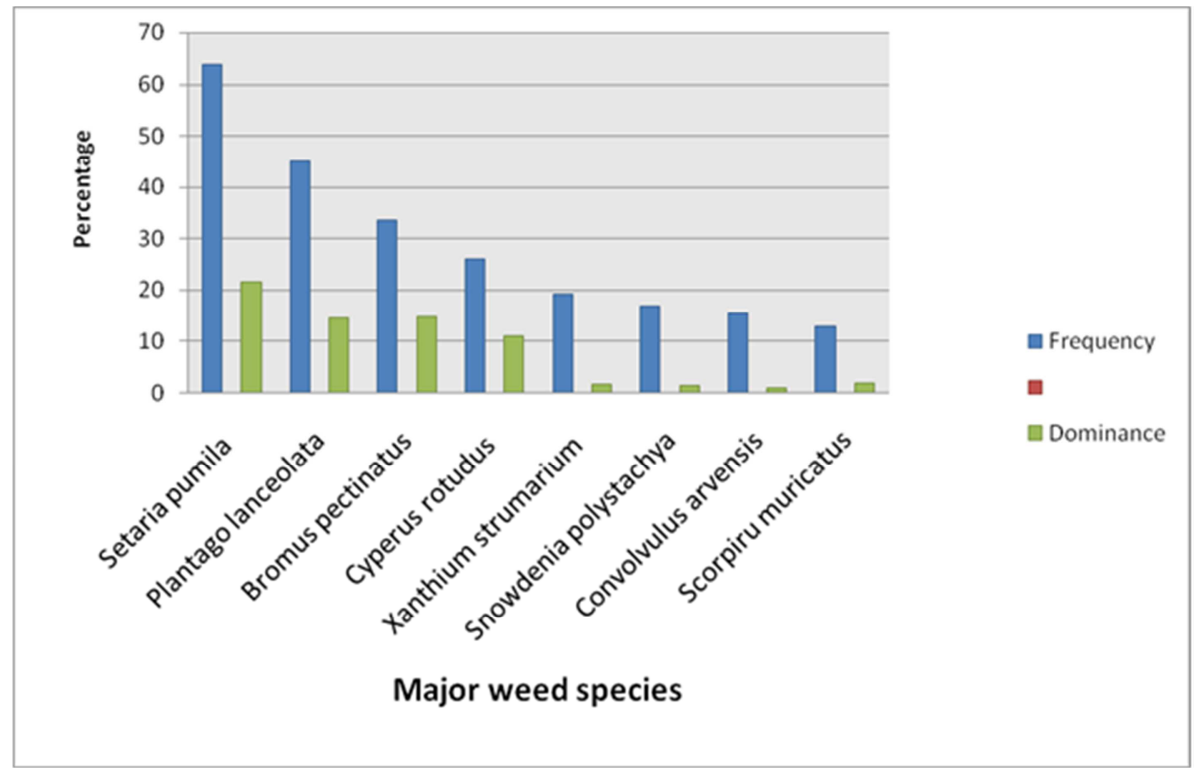

Figure 3. Frequency and Dominance of eight major individual weed species in Wheat.

\subsection{Major Weeds Affecting Wheat Production}

It is quite necessary to have the list of the major weeds in a locality in order to plan a long term weed management strategy for the economic crops [9]. Major broadleaved and grass weeds species that were found infested wheat fields of Ada, Minjar, Lume, Akaki, Gimbichu and Bora districts are Setaria pumila, Plantago lanceolata, Bromus pecpectinatus, Cyperus rotudus, Xanthium strumarium, Snowdenia polystachya, Convolvulus arvensis, Scorpiru muricatus, Oxygonum sinuatum.

\subsection{Similarity Index}

Similarity index (Community index) is an index of the extent to which species compositions existing in any two different crops or locations are similar. The weed flora similarity index of Ada, Minjar, Lume, Akaki, Gimbichu and
Bora districts was above $60 \%$ which means that similar weed management method can be used to control weeds at the two districts.

\section{Summary and Conclusions}

Weed assessment was carried out in wheat fields at Ada, Minjar, Lume, Akaki, Gimbichu and Bora Districts of East Shoa Zone, Oromiya Regional State in 2014/15 main cropping season in order to identify, quantify and prioritize weed species in the area.

A diversified weed flora comprising 44 weed species belonging to 27 families was recorded in wheat fields of the six districts. Some of the broad leaved and grass weeds most prevalent in the area were Setaria pumila, Plantago lanceolata, Bromus pecpectinatus, Cyperus rotudus, Xanthium strumarium, Snowdenia polystachya, Convolvulus arvensis, Scorpiru muricatus and Oxygonum sinuatum. The 
average values for frequency, abundance and dominancy of weeds in wheat were ranged from 0.56 to $64 \%, 0.09$ to 43.2 plants $/ \mathrm{m}^{2} 0.03$ to $21.6 \%$ respectively. The similarity index of the weed community in the six districts of the study area was above $60 \%$ indicating possible use of the same weed control methods at both locations.

Therefore, list of weeds present in each field and their abundance should be considered to select the most appropriate and effective weed management options. In the study area, farmers mostly use Pallas OD 45, 2, 4-D and supplementary hand weeding to control weeds in wheat fields. They do employ weed control in August and September after the weeds have grown tall, resulted crop damage and reduced yield. This clearly indicates the need for awareness creation on the serious negative effect of weeds at early growth stage than later. Results of the current survey work is the first of its kind in the area; and therefore, it can be used in the future to facilitate the designing of site-specific weed management that; and as a source of weed species reference database for the study area.

\section{Acknowledgements}

We gratefully acknowledge Technical and Field assistant those who helped us in all aspects to complete this research work. Secondly, we would like to thank the East Africa Agriculture Project (EAAP) for donating the opportunity to work the research work. Finally, we would like to thank the Ethiopian Institute of Agricultural Research to giving us the opportunity to work on this research.

\section{References}

[1] Akobundu, I. O. 1991. Weeds in human affairs in sub-saharan Africa: Implications for sustainable food production. Weed Technology 5: 680-690.

[2] Barros, J. F. C., G. Basch, and M. de-Carvalho. 2008. Effect of reduced doses of a post-emergence graminicide to control Avena sterilis L. and Lolium rigidum G. in no-till wheat under Mediterranean environment. Crop Protec., 27: 1031-1037

[3] Clark, M. S., H. Ferris, K. Klonsky, W. T. Lanini, A. H. C. Van-Bruggen and F. G. Zalom. 1998. Agronomic, economic, and environmental comparison of pest management in conventional and alternative tomato and corn systems in northern California. Agric. Ecosyst. Environ., 68: 51-71.

[4] IAR (Institute of Agricultural Kesearch). 1985. Progress Report for 1983-1984. pp. 125-128. Department of Crop Protection.

[5] IAR (Institute of Agricultural Research). 1986. Progress Report for 1984-1985. pp. 105-1 II. Department of Crop Protection. APPRC (Ambo Plant Protection Research Centre). 1996.

[6] Liebman, M. and Davis., A. S. (2000) Integration of soil, crop, and weed management in low- external-input farming systems. Weed Research. 40:27-47.

[7] Penfold, C. M., M. S. Miyan, T. G. Reeves and I. T. Grierson. 1995. Biological farming for sustainable agricultural production. Aust. J. Exp. Agric., 35: 849-856. Quanqi

[8] Pohlan, 1. 1984. Arable farming and weed control. Institute ofTropical Agriculture, Plant Production Section, German Democratic Republic. 141 pp.

[9] Stonehouse, D. P., S. F. Weise, T. Sheardown, R. S. Gill and C. J. Swanton. 1996. A case study approach to comparing weed management strategies under alternative farming systems in Ontario. Can. J. Agric. Econ., 44: 81-99

[10] Tamado, T. and P. Milberg. 2000. Weed flora in arable fields of eastern Ethiopia with emphasis on parthenium hysterophorus. Weed research 40: 507-521.

[11] Tanner, D. G., Giref Sahile and Workiye Tilahun. 1995. Competitive ability of Ethiopian spring bread wheat cultivars with Avena fatua L. African Crop Science Journal 3: 83-91.

[12] Unger, 1. 1984. Principles and practices of weed management. Addis Ababa University, College of Agriculture, Alemaya, Ethiopia. 185 pp. 